\title{
Ons Suid-Afrikaanse Regsteoretiese Grondbegrippe Gekonfronteer met die van Prof. Dooyeweerd
}

Tevore (Des. 1956) is reeds hier aangetoon dat ons Afrikaanse regsgeleerdes oor die geheel, in hul geregverdigde reaksie teen die voorheen heersende Angliserende rigting op hierdie gebied, hul beperk het tot 'n terugkeer na die Romeins-Hollandse beskouinge en tot 'n afwending na vastelands-Europese outoriteite. Ook is aangedui dat hierdie reaksie nie voldoende is nie, maar dat gevorder moet word tot 'n eie moderne Suid-Afrikaanse regsteorie wat ook rekening moet hou met ons nasionale Calvinistiese dinkrigting, wat veral deur prof. Dooyeweerd van die Vrije Universiteit te Amsterdam regsteoreties ontwikkel is.

In aansluiting hierby word ons regsteorie in sy twee hoofrigtinge nou hier gekonfronteer met die beskouinge van prof. Dooyeweerd, wat wel nie algemeen selfs onder Calviniste ondersteun of gevolg word nie (soos in 'n vorige artikel deur my in Koers (Febr. 1957) ook reeds vermeld), maar wat tog wesenlik modern en Calvinisties dink en ook onder andersdenkendes oorsee hoog geag word.

Die mees omvattende regsteoretiese uiteensetting deur 'n Suid-Afrikaanse outoriteit hoort tot die Angliserende rigting en word verteenwoordig deur prof. Wille se "Principles of South African Law", 1956.

Hierdie bekende skrywer, professor in Kaapstad, beperk hom tot wat hy noem positiewe of nasionale of staatlike reg, in onderskeiding van natuurreg, billikheid, positiewe moraliteit en volkereg, en meen dat die kenmerke hiervan is dat dit gedragsreëls bevat vir mense binne 'n staat om vrede en orde te verseker. Dit is verder vir hom 'n versameling van reèls wat bindend is en afgedwing word op alle inwoners van ' $n$ 
staat. Die dwang bestaan in 'n sanksie, d.w.s. 'n leed wat aan 'n regsoortreder toegevoeg word, in die vorm van straf of vernietiging van sy handeling in juridiese sin, en wel deur die owerheid, wat ook die reels mak of neerlê deur middel van wetgewing (pp. 1-2).

Hier het ons blykbaar die bekende Engelse teorie van die staatlike regspositivisme. Die reg, eintlik alle reg wat die naam verdien, is staatsbevel met sanksie om samelewingsorde in vrede te verseker. En dit bestaan volgens bl. 4 uit materiële reg en prosssreg - die eerste die eintlike gedragsreëls en die tweede betreffende regsmiddels vir de afdwinging van daardie reëls. Eersgenoemde word verder onderverdeel in strafreg, delikte-, kontrakte-, vermoëns- en personereg. Hierdie regsafdelinge is onderskeidelik daarop gerig om oneerlike, nalatige of trouelose handelinge te verhinder, vlyt te bevorder en belemmerde persone te beskerm. Dit alles hoort ook tot die genoemde Engelse dinkrigting, behalwe miskien die laaste sin, wat ons maar daarby laat as synde slegs 'n baie voorlopige karakteristiek.

Die indeling in onderdele van die materiële reg is blykbaar erg onsistematies en die onderskeiding van die prosesreg gebrekkig. lmmers die prosesreg bevat ook gedragsreèls en het nie net te doen met afdwinging van gedragsreëls nie, maar wel ook met sekerstelling van betwyfelde of liewer betwiste reg deur middel van regspraak.

Maar is alle reg nou staatsbevel met sanksie, en nog wel strafof vernietigingsanksie? Dit is tog wel 'n heel verouderde Anstinianisme. Want selfs as ons die term reg beperk tot staatlike reg (wat in elk geval 'n geweldige vereniging is, veral as ons daaronder verstaan nie alle reg deur die staat gehandhaaf nie, maar alleen reg deur die staat gevorm), selfs dan is daar tog nie in hierdie sin 'n sanksie op alle reg nie. Dit is bekend genoeg. Boondien is ook nie al hierdic reg staatsbevel nie en nog minder wetgewingsbevel. Dit kan ook as teen hierdie tyd bekend veronderstel word, maar later kom ons hierop terug aan die hand van Dooyeweerd se teorie.

Verder is die reg, en selfs "law", nie net 'n stel reëls nie. Immers regte en titels of regsgronde, ens., hoort ook tot die reg. En selfs van die bevelsreëls, sou alle bevele nou reg daarstel? Hoort dit tot die reg as Koning Knoet die see beveel om pad te gee van sy stoel? Maar die staat pas ook reg toe wat hoegenaamd nie eens deur hom gevorm is nie, en wel op 'n geweldige skaal, bv. statute van maatskappye en vereniginge, kontrakte van allerlei persone, ens., ens. (Sien benede). 
Nou word egter in Hoofstuk 11 gesê dat die staatlike reg ook nog sekere essentialia bevat, behalwe dat dit 'n afgedwonge bevel is. Dit moet $\mathrm{nl}$. redelik wees en onpartydig en in ooreenstemming met ,public opinion", prakties toepasbaar, seker, omvattend en ,publicly announced". So nie is dit „abrogated".

Voordat ons kortliks hierop ingaan, merk ons net eers op dat hierdie verdere vereistes met die voorafgaande in stryd is. Want 'n staatsbevel kan bv. afdwingbaar wees sonder om redelik te wees. En selfs as dit nie die geval sou wees nie en hierdie verdere vereistes aanvaar word, dan sou 'n regsreël wat daaraan nie beantwoord nie, nie altyd ,abrogated" wees nie, maar sal dit nooit in gelding tree nie.

Wat dan hierdie vereistes, betref ten opsigte van die inhoud van regsreëls, ten eerste word gesê dat hulle redelik moet wees en dat alle outoriteite daaroor saamstem, d.w.s. de Groot, Voet, Salmond en Allen. Dat alle outoriteite hieroor saamstem, is seker nie waar nie. Boondien is dit geen aanvaarbare vereiste nie. Hier word naamlik nie onderskei tussen regsbegrip en regsidee, tussen die reg soos dit is en soos dit behoort tc wees nie. En wat beteken redelik eintlik? In hierdie verband word verder gesê dat die doel van die reg ook is om die welsyn van die gemeenskap te verseker - dit kom nou by die vrede en orde wat tevore genoem is. Hier word ook na die natuurreg verwys; en dan word gesê dat dit beteken dat die reg bevoordeling van persone bevorder en benadeling teenwerk. Maar dan word heeltemal teenstrydig bygevoeg dat ' $n$ parlementêre wet geldig is, al is dit hoe onredelik of nadelig. Met ander woorde redelikheid, wat dit ook mag beteken, is nie ' $n$ vereiste van alle reg nie. Maar dit is 'n positiewe regsbeginsel met beperkte toepassing. Dieselfde geld min of meer vir die vereiste van onpartydigheid, wat ook genoem word 'n element van redelikheid. In mindere mate geld dit ook van die vereiste dat die reg in ooreenstemming moet wees met 'n wisselende ,public opinion". Die vierde vereiste, nl. dat die reel prakties toepasbaar moet wees, is vanselfsprekend uit die definisie, want daarin is gesê dat die reg reels bevat wat inderdaad afgedwing word. Dit sou koning Knoet se bevel uitskakel, hoewel hulle dit slegs gebruik om bloot inwendige handelinge uit te skakel.

Die vereiste en sekerheid en omvattendheid is van dieselfde soort as die eersgenoemdes. En openbare promulgasie kan alleen op die wettereğ betrekking hê. Eintlik word bedoel dat so veel moontlik bekendheid van die reg bevorder moet word omdat kennis vermoed word.

Tot sover dan wat hulle te sê het oor die regsbegrip en die regs- 
idee sowel as oor die formele en materiële indelinge van die reg.

In die volgende Hoofstuk Ill kom hy tot die bronne van die reg en die proses van regsvorming.

Volgens hom maak of vorm die owerheid die reg, op direkte of indirekte wyse, en wel in die vorme van wetgewing, regterlike beslissing en gewoonte en soms regsgeleerde werke, die eerste genoem wettereg en die ander drie saamgevat as gemene reg. Die eerste word as die voortreflikste beskou. Terugwerkende wetgewing word beskryf as in stryd met "natural justice" en daarom is daar 'n vermoede daarteen. Regterlike beslissing is in uitsonderlike gevalle regsvormend en word dan gegee volgens ,fundamental principles of justice". Die ratio decidendi is in so 'n geval bindend vir soortgelyke gevalle, hoewel nie absoluut nie. Verkeerdelik word egter gesê dat alleen die owerheid 'n regsreël kan wysig wat deur die hoogste hof neergelê is. Omgekeerd kan geen hof die wettereg wysig nie. Ander gebreke van presidente-reg word uiteengesit. Gewoontereg is teenswoordig slegs selde in gelding as sodanig vanweë langdurige „observance by the community as such". Sulke gewoontes beliggaam gebruiklike bindende algemene gedragsreëls, mits hulle redelik is, en lank gevestig en deurgaans in ag geneem word en seker is. Dit alles moet aan die hof bewys word volgens sekere reëls van ons reg. Daarby word verskil gemaak tussen gewoonte en handelsgebruik. O.a. mag gewoontereg nie in stryd met uitdruklike wetteregtelike bepalinge van na 1806 wees nie. Dit word as 'n element van redelikheid behandel. By die deurgaanse inagneming word gesê dat dit gehandhaaf moet word deur die betrokke persone as 'n verpligting. Wat betref regsgeleerde werke, word die ou Romeins-Hollandse skrywers se werke in Suid-Afrika volgens hulle inderdaad as regsbronne aanvaar en wel op grond van gewoonte en tot 'n mate wetgewing. 'n Regsreël kan deur wetgewing herroep word of deur onbruik verval, die laaste wat betref wettereg voor 1806 in Suid-Afrika.

In Hoofstuk IV word „forms of law" bespreek wat nie tot die positiewe reg behoort nie, en wel natuurreg, billikheid, 'n deel van die konstitusionele reg, volkereg en positiewe moraliteit. Die eerste word nog erken as ,principles of natural justice”, veral by die toetsing van ondergeskikte wetgewing deur die howe. Billikheid (equity) wat afsonderlike aanvullende deel gevorm het van die positiewe reg in Rome en Engeland, is 'n algemene beginsel van die Suid-Afrikaanse reg. Hierdie eerste twee regsgebiede hoort dus wel tot 'n mate tot die positiewe reg in sover nog by ons erken. Die konstitusionele konvensies hoort 
volgens hom nie tot die positiewe reg en word nie deur die howe gehandhaaf nie. Hierdie reëls word baie vaag omskryf op bladsy 27. Die volkereg word soortgelyk behandel. En positiewe moraliteit sluit in reëls van eer, mode, etiket, ens., wat vir bepaalde klasse geld, maar nie deur die staat gevorm of gehandhaaf word nie.

Die behandeling van die Romeins-Hollandse reg hoef ons nie op te hou nie, behalwe om te vermeld dat hulle heelwat waarde heg aan Engelse besliss.nge en eindelik aan ,fundamental principles of all law" as leidrade vir die hof (pp. 47-48).

Hoofstuk VII gaan dan weer volledig in op die indelinge van die reg en sê dat die werk verder slegs sal handel oor die materiële burgerlike reg.

Eers word ingedeel in strafreg en burgerlike reg. Strafreg handel oor dic bestrawwing van persone vir misdade en burgerlike reg oor die regte van persone. 'n Misdaad is ' $n$ handeling wat strafbaar is deur d:e staat, gepleeg met "mens rea", altans gewoonlik. In die burgerlike reg lyk 'n delik hierop, maar die verskil is dat hier geen ,mens rea" vereis is nie, maar net skade sonder verskoning of regverdiging, wat die benadeelde persoon reg gee op skadevergoeding.

Dan volg die indeling in Materiële en Prosesreg, nl. in die burgerlike reg, soos tevore, maar effe meer breedvoerig (bl. 51).

Die materiële burgerlike reg word weer ingedeel in ,legal right" en „persons".

'n „Legal right" word gedefinieer (bl. 52) as "an interest conferred and protected by the law, entitling one person to claim..."

Eersgenoemde word verder ingedeel in persoonlike en saaklike regte ens.

Persoon word gedefinieer as „somebody who, or something which, can have legal right and can also be bound by legal rights, i.e. be subject to legal duties", ens., ens.

Verder gaan ons hier nie op in nie, behalwe om net nog op te merk dat persoonlikheidsregte nie onderskei word nie, dat ook nie onderskei word tussen regsbevoegdheid en handelingsbevoegdheid nie en dat nog enkele inleidende opmerkinge gemaak word oor die taal-aspek in die reg, oor algemene regspreuke, oor vermoedens en uitsonderinge op reels.

Oor die geheel dus 'n tipies Engels-georiënteerde taamlik verwarde regsteorie met 'n Romeins-Hollandse sous. Wille se outoriteite op die 
algemene regsleer is dan ook Allen, Austin, Bryce, Del Vecchio, Hibbert, Holland, van Thering, Markly en Salmond.

Op al die onbevredigende aspekte van hierdie regsteorie kan ek hier nie verder uitwei nie. Ons Afrikaanse regsgeleerdes van die vastelands-Europese rigting sal daar ook wel deeglik bewus van wees. Ongelukkig egter het geen een van hulle 'n eie regsteorie probeer ontwerp nie, soos ek wel tentatief van Calvinistiese standpunt probeer doen het in my werkie oor die Algemene Regsleer van 1943.

'n Mens moet dus hulle beskouinge probeer opmaak uit hulle behandeling van die positicwe regstof en met die oog daarop kies ek twee verteenwoordigende werke op die gebied van sowel die publieke as die burgerlike reg. In beide word veral weerspieël die regsteoretiese beskouinge van die bekende prof. J. C. de Wet van Stellenbosch, wat bekend is as vurige en bekwame voorstander van die volledige herstel van die Romeins-Hollandse reg in Suid-Afrika.

Hierdie werke is die bekende handboeke van drr. De Wet en Swanepoel, Strafreg, 1949 en De Wet en Yeats, Kontrakte en Handelsreg, 1953.

Die metode in die Strafreg is oor die algemeen histories-posivisties, met die daarby passende dogmatiese sistematiek, en verteenwoordig op hierdie stadium seker meer bepaald prof. De Wet se opvatting.

Die reg word heel in die algemeen beskryf as die orderende faktor in die samelewing sonder onderskeiding van ander ordenende faktore. Dit is al dadelik histories. En meteens is daar ook moeilikheid met die onderskeiding tussen publieke en privaatreg. Vireers word verkeerdelik gesê dat alle reg oorspronklik privaatreg was en dan dat die onderskeiding tussen die twee kunsmatig is. (bl. 1 en 2).

Die sistematiek is verder ook gebrekkig in sover aan die strafreg nie 'n duidelike plek in die staatsreg toegeken word nie. Daar word ook m.i. onnodiglik gesoek na 'n regverdiging van die strafreg (bll. 4 v.v.). Bedoel word eintlik 'n regverdiging van straf. Maar strafreg omvat meer as straf, dit gaan eintlik oor misdade en hulle regsgevolge, vgl. Engels „Criminal Law".

Ook die omskrywing van misdaad lyk nie heeltemal bevredigend nie. Op bladsy 7 word dit naamlik genoem: skuldige wederregtelike menslike gedraging wat met straf bedreig word, d.w.s. die leed wat die oortreder weens die oortreding toegevoeg word ná vonnis deur 'n van die uitvoerende gesag onafhanklike hof. Die elemente van die misdaad word genoem die menslike handeling, die weder- 
regtelikheid daarvan, die skuld van die dader en die strafbedreiging. Hier word oorsaaklikheid en toerekenbaarheid nie genoem nie. Ons kom hierop later in 'n ander artikel terug.

Maar merk nou net op dat strafbedreiging seker nie 'n element van die misdaad is nie, maar van die norm wat die misdaad verbied. Strafaanspreeklikheid is dus 'n regsgevolg van 'n misdaad en nie 'n element daarvan nie.

Hierdie verwardheid en die strewe om die strafreg te regverdig skyn vir my die gevolg te wees van die historisme wat moet uitloop in 'n gebrekkige sistematiek, omdat die reg nie in sy eie aard gevat word nie, maar as 'n kultuurproduk naas ander.

'n Regverdiging van straf en strafreg skyn vir my bv. nie meer noodsaaklik te wees as dié van enige ander afdeling van die staatlike reg nie. Dit is tog maar 'n sistematiese onderdeel van die staatsreg, wat verval in konstitusionele reg en administratiewe reg, net soos die burgerlike of staatlike privaatreg in reg van persone en van "sake". Strafreg is spesiale onderdeel van die administratiewe reg.

Want die administratiewe reg bepaal hoe die staat meer bepaald as uitvoerende gesag in regsverhoud:nge te staan kom. Een belangrike vertakking hiervan is die reg van die staat om straf op te lê as vergelding vir misdaad, d.w.s. skending van die staat se subjektiewe reg as staat.

Hoofstuk III gaan verder op die elemente van die misdaad in. Hier tref 'n sekere neiging tot onjuridiese naturalisme of psigologisme, wat gewoonlik uit die historisme voortvloei.

Op bl. 17 word bv. gesê dat misdaad is 'n waarneembare menslike gedraging; en dat dit willekeurig moet wees, maar nie noodwendig gewild nie; en op bl. 19 dat 'n regspersoon geen misdaad kan pleeg omdat hy geen skuld kan hê nie; en dit wel ondat hy 'n ideële (sic!) ding is.

In dit alles en wat direk volg, word blykbaar gedink aan 'n handeling in fisiese of psigiese sin. Maar daardie aspekte van 'n handeling is vir die reg maar net substraat. In die reg self is 'n handeling 'n subjektiewe juridiese feit wat aan 'n persoon toegereken word, enkeling sowel as groepspersoon, en wel op grond van regsoorweginge. 'n Handeling in juridiese sin hoef dus nie noodwendig psigies te bestaan nie en ook nie uitwendig waarneembaar te wees nie; wel moet 'n misdaad altyd gevolge hê in die regslewe, d.w.s. dit moet steurend in die regsbelange ingryp. 'n Misdaad is dus altyd juridies oorsaaklik, selfs formele 
misdade en poginge, ens. Dit affekteer altyd die ewewig in die regsbelange, dit skend altyd 'n publieke reg. Aanders kan dit geen misdaad wees nie. Bv. om sonder 'n rooi-lig te ry skep 'n gevaar vir die verkeer en het dus 'n oorsaaklike werking in juridiese sin.

Inderdaad by die kousaliteitskwessie op bll. 23 v.v. stuit ons op 'n hardnekkige naturalisme by die outeur. Daar word blykbaar nie ingesien dat die kousaliteitsvraag in, en met name die strafreg, in die reg altyd 'n juridiese kousaliteit betref. Ons soek hier altyd na 'n verband tussen 'n regskending as gevolg en 'n aan 'n subjek toerekenbare handeling as oorsaak. Dit word deur die outeur eintlik net erken by die sogenaamde gevolgsdelikte, juis omdat hy nie die kousaliteit sien as universele juridiese skakel tussen regsgrond en regsgevolg in die subjeksaspek van die reg nie.

Hieroor het ek reeds vroeër in die aanhangsel tot my boekie oor die Algemene Regsleer, enigsins verward, geskryf en ek kom later dan ook terug op die strafregtelike aspekte na aanleiding van hierdie uitnemende handboek onder bespreking, in 'n positief-konstruktiewe sin en wel in 'n afsonderlike artikel oor die strafregtelike kousalite't. Ek wys nou slegs op enkele verdere historistiese, naturalistiese en psigologistiese voorstellinge in die "Strafreg", met 'n enkele verwysing ook na die „Kontrakreg”, waar prof. De Wet blykbaar ook die regsteorie hoofsaaklik bepaal.

In verband met die kousaliteitsvraag merk ek nog net op dat die condicio sine qua non-leer wat so fanaties aangehang word, heeltemal naturalisties en in sigself nie juridies van strekking is nie. Daarom kan die outeur ook nie kousaliteit by alle misdade sonder uitsondering aanvaar nie. In die strafreg is dit eintlik die regskendende wederregtelikheid wat oorsaaklik is en dit is ' $n$ juridiese kategorie.

Histories is bv. ook die hele opvatting van die gemene as 'n grewoonteproduk en psigologisties die opvatting van skuld as 'n psigies aanwesige houding.

Beide standpunte kry ons ook in die Kontrakreg verteenwoordig, laasgenoemde bv. in die stelling dat wilsooreenstemming die wese van kontrak uitmaak, in die sin van eensgesindheid van die partye ten aansien van die beoogde gevolge. (bl. 8).

Wat eersgenoemde standpunt betref, hoewel De Wet die reg in wese beskou as staatsproduk, gee hy tog altyd die voorkeur aan die gemene reg bo die wettereg. 
In die „Kontrakreg” is ook meer opvallend die positivistiese instelling van die outeurs in sover blykbaar net die staatlike reg erken word, aangesien hier anders as in die strafreg wel aanleiding bestaan het om te verwys na nie-staatlike reg. Die skrywers onderskei wel die Suid-Afrikaanse reg in gemene reg en wettereg, maar wek tog die indruk dat die gemene reg 'n soort staatsgewoontereg beliggaam, hoewel hulle hul hier nie duidelik oor uitspreek nie. Tog wys hulle meermale herhaalde stelling dat alle reg oorspronklik privaatreg was, omdat daar toe nog geen staat was nie, wel daarheen dat hulle in historistiese sin die gemene reg weer beskou as 'n produk van die volksgemeenskap.

In die Strafreg word selfs sterk staats positivisties gesê dat die wetgewer almagtig is op sy terrein; tog skroom die outeur hier ook nie om ' $n$ bepaalde wet te beskryf as strydig met die goeie beginsels van die strafreg, dus met ' $n$ regsidee wat in sigself nie noodwendig positief is nie. (bl. 21).

My bedoeling is egter ook hier nie om breedvoerig kritiek te oefen nie, maar net om dic onderliggende regsteorie redelik voldoende te kenskets, sodat teenoor beide die tot nog toe behandelde hoofrigtinge in ons Suid-Afrikaanse regsteorie die fundamentele opvattinge van prof. Dooyeweerd met vrug afgeteken kan word.

Behalwe al lank deur my, en later deur prof. W. A. Joubert van Bloemfontein, is prof. Dooyeweerd se teorie onlangs vermeld deur prof. dr. J. P. Verloren van Themaat, nou van Pretoria, in sy uitnemende handboek oor die Staatsreg van 1956.

Sy eie regsteorie het egter blykbaar nog nie die invloed van Dooyeweerd ondergaan nie en kan grotendeels gelykgestel word met dié van prof. De Wet. Trouens hy laboreer blykbaar ook aan 'n fundamentele misverstand van wat Dooyeweerd bedoel met regsbeginsels, deur hierby regsbegrip en regsidee te verwar, soos hopelik uit wat volg, duidelik sal word.

Dat Dooyeweerd origens prof. Verloren van Themaat se eie regsteorie nie sterk beïnvloed het nie, kan bv. blyk uit sy definisie van die staat as ' $n$ regspersoon. In die gees van Dooyeweerd sou dit seker beskryf moet word as 'n eensydige opvatting, aangesien volgens laasgenoemde die staat veel meer is as net ' $n$ regspersoon. Dit is naamlik 'n menslike samelewingsvorm wat baie ander aspekte het as bloot die juridiese, en in die juridiese aspek ook meer as die van regspersoonlikheid.

Trouens iets of iemand is ' $n$ regspersoon slegs as draer van regle 
en verpligtinge teenoor ander persone. So kan die staat as regspersoon optree teenoor ander state in die volkereg en teenoor privat persone in die burgerlike reg, en teenoor onderdane in die strafreg en die administratiewe reg, hoewel ons in laasgenoemde geval meer met die uitvoerende orgaan van die staat as met die staat self as geheel te doen het.

Maar behalwe regspersoon teenoor ander persone is die staat intern 'n organisasie met verskillende organe van die owerheid teenoor mekaar en teenoor die onderdane, en hiermee veral het die staatsreg te doen. $E n$ in hierdie verband beskou ons die staat nie as regspersoon nie, maar as 'n gemeenskap van mense in sy regsaspek, net soos oor die interne juridiese verhoudinge kan vasstel van 'n huisgesin of 'n vereniging, sonder om hulle as regspersoon te beskou, wat hulle dan ook in die positiewe reg gewoonlik nie is nie.

M.a.w. die regsaspek van die staat is saamgeskakel met sy ander aspekte in die werklikheid en dit bring mee dat die reg ook die staatsreg, 'n beliggaming is van beginsels wat verband hou met al die aspekte van die werklikheid.

Ten opsigte hiervan het die skrywer ook prof. Dooyeweerd blykbaar misverstaan: as laasgenoemde naamlik verwys na regsbeginsels wat in die reg gepositiveer word, dan dink hy nie in eerste instansie aan wat die reg behoort te wees nie (die sg. regsidee), maar aan wat die reg werklik is (die regsbegrip).

As hy bv. verwys na die vroeëre Russiese huwelikswetgewing wat egskeiding vrylaat, dan sê hy dat dit geen huweliksreg daarstel nie, aangesien die huwelik in sy wese nie willekeurig ontbindbaar is nie. Dit kan slegs beteken dat die staat hom nie bemoei met egskeiding nie, maar in die regslewe self ook in Rusland sou die regsverkeer wel meebring dat egskeiding op verskillende maniere beperk is, so seer dat die staat ook later hierin weer moes ingryp.

En as Dooyeweerd sê dat die mens as persoon geen regsobjek kan wees nie, dan beweer hy nie dat sekere aspekte van die persoonlikheid nie regsobjek kan wees soos bv. in die slawerny nie; maar wel dat die persoonlikheid as sodanig geen regsobjek kan wees nie, wat bv. daaruit blyk dat dit onmoontlik is om 'n persoon se denkprosesse of etiese wilsrigting of geloofsekerhede juridies te beheers.

Hierin word verwys na bl. 15 in die genoemde werk van prof. Verloren van Themaat, wat alleen daaruit verklaar kan word dat hy nog nie ten volle deurgedring het tot die insig dat die reg ook bowillekeurige beginsels beliggaam en dat die reg ook gevorm word in 
baie ander kringe van samelewing as die staat nie, hoewel hy blykbaar enige besef hiervan het.

Maar wat dit betref, ly al die genoemde skrywers nog aan die 19e eeuse positivistiese vooroordele van verskillende soort.

Hierop sal ons nou kortliks nader in die algemeen ingaan, nie deur immanente of transsendente kritiek nie, maar deur positief daarteenoor te stel die grondgedagte van Dooyeweerd se regsteorie wat hom stempel as modernis en Calvinis tegelyk.

Prof. Dooyeweerd se eerste fundamentele regsteoretiese bydrae is dat die reg 'n onherleibare modaliteit of aspek van die werklikheid is, wat tog oog weer in 'n bepaalde orde saamgeskakel is met alle ander werklikheidsaspekte, sodat dit op die meeste ander gefundeer is, maar antisipeer op twee wat meer gekompliseerd is, nl. dié van sedelikheid en geloof.

Die reg kan dus nie gedefinieer word deur dit tot iets meer algemeens te herlei nie; dit kan ook nie van ander aspekte van die werklikheid onderskei word deur bloot formele kenmerke, bv. dat dit dwingend sou wees of betrokke op eksterne gedrag ens. nie. Dit hoort wel tot die normgebied van die werklikheid in onderskeiding van die natuurgebied, omdat dit menslike vorming vereis om tot gelding te kom, anders as die natuurwette. Die onherleibare kwaliteit van die reg word deur Dooyeweerd dikwels beskryf as vergelding in die ruimste sin, d.w.s. die verbinding van regsgevolge aan regsgronde. Geen van die Suid-Afrikaanse teorieë, soos uit die voorgaande blyk, het hierdie insig reeds bereik nie. Die moderne teorie van Hans Kelsen streef wel daarna, maar volgens Dooyeweerd herlei hy die reg tot normlogika, wat dit eensydig vervals.

Ten tweede vloei vir Dooyeweerd uit bostaande voort dat die reg gevorm is uit regsbeginsels wat dit tot reg maak, en wel formele en materiële beginsels, wat bo-willekeurig is, ondat dit in die werklikheidsverband van die reg gegrond is. Hiermee word nie in eerste instansie bedoel beginsels van wat die reg behoort te wees, soos die natuurregsteorie probeer ontwikkel het nie, maar beginsels van die positiewe reg soos hy werklik bestaan. Hierdie beginsels is gedeeltelik staties, bv. die voorhistoriese, en gedeeltelik dinamies, soos dié wat in die historiese aspek gegrond is. Vanaf Geny het hierdie soort beskouinge veld gewen, maar Dooyeweerd onderskei hom weer daarin dat hy hierdie beginsels as juridiese elemente handhaaf.

'n Voorbeeld van ' $n$ statiese beginsel is dat die huweliksreg ' $n$ be- 
sondere regsbetrekking daarstel tussen man en vrou. Dit is in die fisiologiese natuuraspek van seksverhoudinge gegrond. 'n Voorbeeld van 'n dinamiese beginsel is dat die staat ' $n$ gemeenskap is van owerheid en onderdane wat geweld territoriaal monopoliseer tot daarstelling van 'n gemeenskaplike regsorde. Dit is dinamies omdat dit eers in die geskiedenis ontwikkel.

In die regsbeginsels onderskei Dooyeweerd verder tussen dié wat verbonde is met die regsbegrip, dus die reg tot reg maak, en dié wat verbonde is met die regsidee, d.w.s. die geldende reg tot hoër ontwikkeling wil opvoer deur te stel hoe die reg behoort te wees. Hierin volg hy die neo-Kantiane, maar met die verskil dat hy die regsidee nie bloot formalisties behandel nie. Die regsidee is steeds werksaam in die regsbegrip en antisipeer allereers op die sedelikheid. Straf volgens skuld is bv. ' $n$ beginsel van die regsidee wat ook in ons strafregsteorie erken word. Maar ons regsteorie beskou die regsbeginsels hoofsaaklik as gegee in die positiewe reg, en sien nie in dat hulle ook voorpositief is en die positiwering bepaal nie.

In die derde plek onderskei Dooyeweerd konsekwent tussen die wetsaspek van die reg, d.w.s. die sisteem van norme, en die subjeksaspek, of die sisteem van regsverhoudinge. Maar beide word deur hom tot die regsgebied gereken en ook die subjeksaspek is dus juridies bepaal en nie natuur-kousaal of andersins ajuridies nie. Bv. 'n persoon in die reg is nie die mens in sy volheid nie, maar is regsubjek; en 'n wil in die reg is nie 'n psigiese verskynsel nie, hoewel daarop gebaseer, maar dit is 'n juridies toegerekende wil as oorsaaklikheid wat psigies miskien glad nie bestaan nie. So ook is juridiese kousaliteit iets anders as fisikaliese kousaliteit, want dit veroorsaak 'n wysiging in regsverhoudinge. Oor hierdie sake is ons Suid-Afrikaanse regsteorieë ook blykbaar nog in die duister, soos uit die voorgaande blyk en later afsonderlik meer breedvoerig uiteengesit sal word.

In die vierde plek erken Dooyeweerd wel geen ander geldende reg behalwe positiewe reg nie, maar stel hy baie beslis, saam met die moderne sosiologiese teorie, dat elke menslike samelewingsvorm, en nie net die staat nie, 'n eie by hom passende reg positiveer deur sy bevoegde organe. Daarom stel hy ook pertinent die probleen wat in die moderne tyd van groot betekenis is, nl. van die verhouding tussen die staatlike en die nie-staatlike reg en van die verhoudinge tussen die verskillende kringe van nie-staatlike reg, soos bv. kerkreg, interne bedryfsreg, ens. ens. Hierdie menslike samelewingsvorme wat almal ook 
regsvormend optree, word deur hom, volgens die gangbare sosiologiese teorie, hoofsaaklik onderskei as gemeenskappe of verbande, d.w.s. georganiseerde gemeenskappe, en maatskappe, in die eerste waarvan mense verenig word tot 'n omvattende eenheid onder gesagdraers, en in die tweede waarvan hul newegeskik langs mekaar optree. Elke samelewingsvorm het as sodanig bevoegdheid om reg te vorm volgens sy aard en bestemming, wat deur die toepaslike werklikheidswetmatighede bepaal word. Dit is 'n regsbeginsel wat in die sosiale werklikheidsaspek gegrond is en is voorpositief en nie afhanklik van staatserkenning nie. Die staat is een van die verbande, daardeur gekenmerk dat dit gegrond is in 'n tipiese historiese magsvorming, maar in besonder daardeur dat dit, alleen van alle verbande, tot bestemming het om 'n territoriaal-gemeenskaplike regsorde te ontwikkel tot integrasie van alle ander reg op die staatsgebied.

In die vyfde plek baseer Dooyeweerd die teorie van die regsbronne op die onderskeiding net gemaak tussen sosiaal-gevormde regskringe, en stel hy ' $n$ baie duidelike opvatting van regsbron as die regsvorm waarin regsbeginsels tot positiewe reg gevorm word deur die bevoegde organe van elke regsgemeenskap of regsmaatskap. Wat die staatlike reg betref, val dit dan hoofsaaklik uiteen in staatsreg, wat die staatlike verbandsreg is, en burgerlike reg, wat die staatlik gevormde integrerende maatskapsreg is vir alle staatsonderdane sonder onderskeid.

Verder wil ek hier nie ingaan op Dooyeweerd se beskouinge oor die regsbronne en die regsindelinge nie. Slegs wil ek pertinent die aandag daarop vestig dat sy onderskeiding van staatlike en nie-staatlike reg modern en korrek en uiters belangrik is, en dat dit besondere lig werp op die aard van bv. gewoontereg, iets waaroor ons regsteorie in die duister is, en ook van die sg. ekonomiese reg, wat in alle moderne staatlike regsordes van buitengewone belang is.

Vir Dooyeweerd is laasgenoemde die ekonomies gekwalifiseerde reg wat gevorm word deur die verbandelike en maatskaplike kringe van die sosiaal-ekonomiese lewe, en geïntegreer word in die staatlike reg, veral burgerregtelik en administratief-regtelik, maar ook strafregtelik.

Van dit alles skyn ons regsteorie nog weinig besef te hê. En tog spring dit by enige nadenke baie sterk in die oog hoeseer selfs die reg wat deur die staatshowe toegepas word, grotendeels nie-staatlik van oorsprong is, veral nok op die terrein van die sosiaal-ekonomiese reg. Neem bv. enige kontrak op daardie gebied wat as sodanig deur die staat as bindend erken word. 
Die terme daarvan egter is gewoonlik slegs in geringe mate deur die staat se burgerlike of ander reg bepaal, bv. in die sogenaamde essentialia van 'n kontrak; grotendeels word hulle egter bepaal deur die kontrakspartye self of deur groepe belanghebbendes in die betrokke bedryfsvertakking, soos bv. wat betref die gebruiklike bedinge, of standaard-terme of kollektiewe arbeidskontrakte, ens.

Hopelik is hiermee genoeg gesê om die belang van Dooyeweerd se beskouinge vir ons regsteorie aan te dui. Dit moet verwelkom word dat prof. Verloren van Themaat, in sy reeds genoemde belangrike handboek oor die Staatsreg, pertinent die aandag daarop gevestig het, en wel in 'n simpatieke gees. Ook hy egter sou voordeel kan trek uit 'n nadere kennismaking daarmee, en veel te meer nog ons ander wetenskaplike juriste, sonder dat hulle Dooyeweerd slaafs hoef na te volg.

L. J. DU PLESSIS.

N.S. Prof. dr. H. L. Swanepoel skryf na aanleiding hiervan o.a. soos volg aan my:

Dit is waarskynlik onjuis om te sê dat alle reg oorspronklik privaatreg was, maar dit bly moeilik om presies vas te stel wanneer en hoe privaatreg en publieke reg histories onderskeie raak, al is die woord „kunsmatig" in hierdie verband nie gelukkig nie.

Die ontleding van die misdaad in sy elemente kan verbeter word, en oor die verhouding tussen strafreg en administratiewe reg sal 'n duideliker standpunt ingeneem moet word.

Die juridiese aard van die handeling in die algemeen, met deeglike rekeninghouding met dic psigiese en fisiese elemente, moet suiwerder uitgewerk word.

Dat ' $n$ misdaad altyd gevolge moet hê in die regslewe, kan toegegee word as 'n mens dink aan die versteuring van regsbelange. Dan word die onderskeid tussen materiële en formele misdade ook minder belangrik, hoewel daar wel 'n onderskeid gemaak kan word na aanleiding van die geskonde belange.

Die behandeling van die kwessie van kousaliteit, soos tot nog toe gegee, is onbevredigend en ' $n$ verbetering van die teoretiese uiteensetting in hierdie verband is dringend noodsaaklik.

Die beskouinge van Dooyeweerd kan hiertoe belangrike hulp bied.

L. J. du P. 